Al1102 485866

NATL INST OF STANDARDS \& TECH RIC

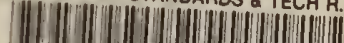

A111024858

Onlemiller, A1 Thomas J/Smoldering combust

IV BDIN OS- 3294

\title{
Smoldering Combustion
}

REFEAENCE

NBS

PUBLICATIONS

T. J. Ohlemiller

U.S. DEPARTMENT OF COMMERCE

National Bureau of Standards

National Engineering Laboratory

Center for Fire Research

Gaithersburg, MD 20899

February 1986

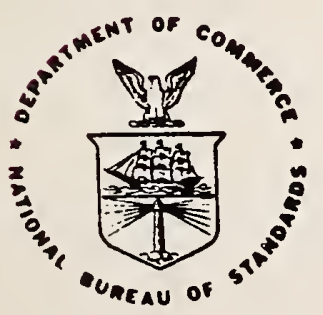

U.S. DEPARTMENT OF COMMERCE

NATIONAL BUREAU OF STANDARDS

$-Q C$

100

.456

$85-3294$

1986 

NBSIR 85-3294

\section{SMOLDERING COMBUSTION}

T. J. Ohlemiller

U.S. DEPARTMENT OF COMMERCE

National Bureau of Standards

National Engineering Laboratory

Center for Fire Research

Gaithersburg, MD 20899

February 1986

U.S. DEPARTMENT OF COMMERCE, Malcolm Baldrige, Secretary NATIONAL BUREAU OF STANDARDS, Ernest Ambler, Director 

Table of Contents

Page

List of figures • • • • • • • • • • • • • • • • • • • v v

Llst of Tables . . . . . . . . . . . . . . . . . . vi vi

1. INTRODUCTION

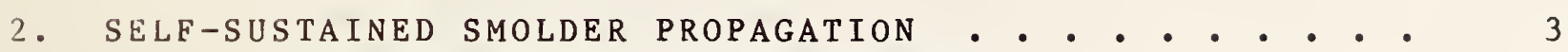

2.1 One-Dimensional Smolder Spread . . . . . . . 4

2.1.1 Reverse Propagation........ . 4

2.1.2 Forward Propagation . . . . . . . . 9

2. 2 Multi-Dimensional Smolder Spread . . . . . . 10

2.2.1 Horizontal Fue1 Layer. . . . . . . . . 10

2.2.2 Other Fuel Configurations....... . 15

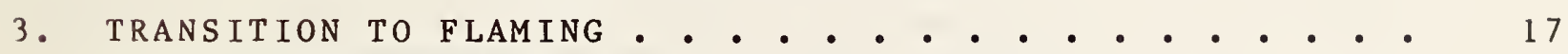

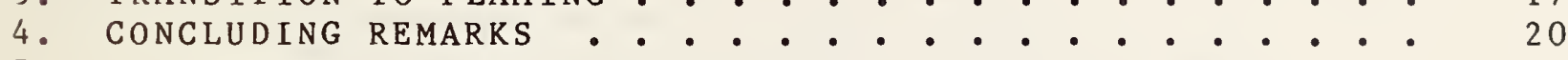

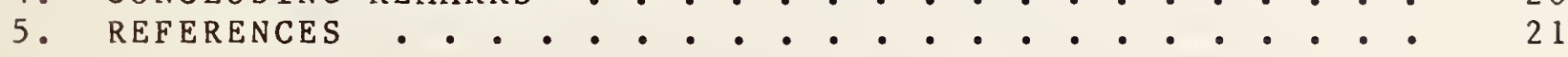



Figure 1. Smoldering upward from bottom within thick layers of mixed wood sawdust (from ref.4); $\square$ initlating layer $2.5 \mathrm{~cm}$ deep, $30 \mathrm{~cm}$ square box; $\diamond$ initiating layer $5.2 \mathrm{~cm}$ deep, $30 \mathrm{~cm}$ square box; $\Delta$ initiating layer $5.2 \mathrm{~cm}$ deep, $60 \mathrm{~cm}$ square box; 0 initiating layer $5.2 \mathrm{~cm}$ deep, $90 \mathrm{~cm} s q u a r e$ box. . . . . . . . . . 26

Figure 2. Smolder velocity vs. air flow velocity into reaction zone for nearly one-dimensional reverse smolder. Symbol $P_{B}$ is bulk density. Material A - ref. 7; Material B - ref. 5;

Material C - ref. 8; Material D,E - ref. 9. . .

Figure 3. Dependence of smolder propagation rate through horizontal layers of beech sawdust on air velocity over top of layer (from ref. 4). $0120 \mu \mathrm{m}$ mean particle size; $\Delta 190 \mu \mathrm{m}$ mean particle size; $\square 480 \mu m$ mean particle size. . 
List of Tables

Page

Table 1. Data on Multi-dimensional Smolder in Various Fuels... . . . . . . . . . . 
SMOLDERING COMBUSTION

T.J. Ohlemiller

Center for Fire Research

National Bureau of Standards

\section{I) Introduction}

Smoldering is a slow, low temperature, flameless form of combustion, sustained by the heat evolved when oxygen directly attacks the surface of a condensed phase fuel. It constitutes a serious fire hazard for two reasons. First, it typically yields a substantially higher conversion of a fuel to toxic compounds than does flaming (though more slowiy). Secondly, smoldering provides a pathway to flaming that can be initiated by heat sources much too weak to cause a flame directly.

A burning cigarette is a familiar example of this flameless mode of combustion; it is also one of the most common initiators of smoldering in other materials, especially upholstery and bedding [1]. A cigarette also has several characteristics common to most materials which do smolder. The finely divided fuel particles provide a large surface area per unit mass of fuel which facilitates the surface attack by oxygen. The permeable nature of the aggregate of fuel particles permits oxygen transport to the reaction site by diffusion and convection. At the same time, such aggregates of particles typically form fairly effective thermal insulators that help slow heat losses and permit sustained combustion despite low rates of heat release.

These physical factors favoring smoldering must be complemented by chemical factors as well. Like virtually all other cellulosic materials, tobacco in a cigarette, when degraded thermally, forms a char. A char is not 
a well-defined material but typically it is considerably richer in carbon content than the original fuel and its surface area per unit mass is also enhanced. This char has a rather high heat of oxidation and is susceptible to rapid oxygen attack at moderate temperatures $\left(\gtrsim 400^{\circ} \mathrm{C}\right)$. The attack of oxygen (to form mainly $\mathrm{CO}$ and $\mathrm{CO}_{2}$ ) is facilitated not only by the enhanced surface area but also by alkali metal impurities (present in virtually all cellulosic materials derived from plants) which catalyze the oxidation process [2]. Char oxidation is the principal heat source in most self-sustained smolder propagation processes; the potential for smoldering combustion thus exists with any material which forms a significant amount of char during thermal decomposition. (Char oxidation is not always the only heat source and it may not be involved at all in some cases of smolder initiation, see below and reference 3.)

Various quantitative combinations of the above physical and chemical factors can produce a material which will undergo sustained smoldering in some conditions. The range of factors is enormous and results in materials which will only smolder when formed into fuel aggregates many meters across, at one extreme, to materials which smolder when formed into aggregates only a few tens of microns across. Unfortunately, a body of theory which allows one to calculate which materials and which conditions are conducive to smoldering has been developed only for certain types of smolder initiation (see section on Spontaneous Combustion). Conditions which are sufficient to yield smolder initiation, especially near an external heat source, are not necessarily sufficient to assure self-sustained smolder spread away from the initiation region. The potential transition of the smolder process into flaming combustion is even less correlated with factors determining smolder initiation. 
This section is restricted to consideration of post-initiation behavior of smoldering. There are a few models of smolder propagation in the literature but none can yet be said to have any practical usefulness; the state of modeling is reviewed elsewhere [4]. Lacking any definitive theoretical description, we are largely restricted here to examining typical experimentally determined behavior. In this overview of smoldering, an attempt is made to convey some of the qualitative interplay of processes that determine overall behavior together with specific experimental results.

\section{II) Self-Sustained Smolder Propagation}

The smolder initiation process is dominated by the kinetics of the oxidation of the solid; subsequent propagation of smolder is controlled, however, to a large degree by the rate of oxygen transport to the reaction zone. This comes about because the heat evolved during initiation raises the local temperature, and thus the local reaction rate, until all of the neighboring oxygen is consumed. Subsequently, the reaction continues to consume oxygen as fast as it reaches the reaction zone, yielding a very low oxygen level locally which limits the rate.

The subsequent evolution of the smoldering zone away from the initiation region is heavily influenced by oxygen supply conditions. If initiation occurs deep within a layer of fine particles (e.g., sawdust, coal dust), for example, it will slowly work its way to the nearest free surface at a rate dictated by oxygen diffusion through the particle layer. (The more coarse and loosely packed the particles, the greater the influence of buoyant flow through the fuel leading to predominant upward spread.) When it reaches the 
free surface region it will spread more rapidly over this region in response to local convective and diffusive oxygen supply conditions. As will be seen, when smolder spread over the surface region of a fuel layer is forced by air flow its response depends in addition on heat transfer considerations.

In examining self-sustained smolder propagation and its response to oxygen supply conditions, dimensionality is important; it is necessary to distinguish one-dimensional from multi-dimensional configurations. It is further necessary to discern whether the smolder zone is spreading in the same direction as the net movement of oxygen or in the opposite direction.

\section{II-A) One-Dimensional Smolder Spread}

This is an idealized situation that is sometimes approximated in real fires; for example, the spread outward or upward from deep in a layer of fuel particles, mentioned above, approaches this limit when oxygen diffusion dominates convection and any curvature of the reaction front is small compared to the reaction zone thickness. In practice this curvature requirement would likely be met by spread away from ignition sources about 10-20 cm in extent.

Reverse Propagation. When oxygen diffuses to the reaction zone, in this particular example, from the outer surface of the fuel layer, through the unburned fuel, toward the reaction front, it is moving opposite to the direction of smolder propagation; such a case of relative movement is termed reverse smolder. It is one of two possibilities for movement of oxygen flow relative to the smolder front; the second case is considered briefly later in this discussion. 
Palmer [5] examined this diffusive reverse smolder case using layers of wood sawdust of various depths; the configuration was only roughly onedimensional. Some of his results are shown in Fig. 1. Note that the time scale is in hours; the time to smolder up through a layer $1 \mathrm{~m}$ deep is about two weeks, a surprisingly long time. Palmer noted that in this configuration the smoldering process gave little hint of its presence until it was close to the surface of the fuel layer.

The slope in Fig. 1 indicates that the time for smolder to penetrate a fuel layer in this mode is nearly proportional to the square of the layer depth [5]. Palmer showed that one would expect exactly a second power dependence on layer depth if it is assumed that the smolder reaction zone propagation velocity is proportional to the one dimensional diffusion rate of oxygen from the surroundings through the unburned fuel, to the reaction zone. From this one gets

$$
t_{L}=A L^{2}
$$

where $t_{L}$ is the time for the smolder zone to penetrate the layer of thickness $\mathrm{L}$; $\mathrm{A}$ is a constant that can, at present, only be determined by experimental measurement of at least one layer thickness. Note that this relation and Figure 1 imply that a $10 \mathrm{~m}$ fuel layer depth, such as might be encountered in a land fill or coal mine tailing pile, would require more than four years for smolder penetration. In practice such a deep layer is unlikely to be uniform and the smolder front movement would be dominated by buoyant convective flow in regions of lesser flow resistance. However, this does illustrate how very slow some smolder processes can be. 
A key factor in the existence of stable, self-sustaining smolder at such extremely low rates is a well-insulated reaction zone. The heat loss rate cannot exceed the heat generation rate. In this case, the same factor which is slowing the oxygen supply rate and, therefore, the heat generation rate, (i.e., the thick layer of wood particles over the reaction zone) is also slowing the heat loss rate.

In the above example, the smolder propagation process is inherently unsteady because of the time-dependent oxygen supply process. If oxygen is instead continually supplied by a forced convective flow through the fuel layer, nearly steady propagation occurs. Such a configuration is encountered in some incinerators and coal burners but rarely in a smoldering fire. Its main interest is that it has been examined experimentally [6] and modeled [7], so it is a relatively well-understood smolder mode whose underlying mechanisms are qualitatively similar to the transient case discussed above.

In this mode of reverse smolder propagation, oxygen surrounds the fuel particles as they are heated by the advancing smolder reaction zone. Thermal degradation of some fuels in the presence of oxygen is exothermic. This is particularly true of cellulosic materials and this heat can be sufficient to drive the smolder wave without any char oxidation [6]. In flexible polyurethane foams, the presence of oxygen during degradation plays another key role. Without it many foams do not form any char [7] and here char oxidation is a necessary source of heat. In any event, in the reverse smolder mode, the net oxidation rate (and net heat release rate) is again directly proportional to oxygen supply rate; the smolder zone spreads to adjacent material as fast as this generated heat can be conducted to it. Increased oxygen supply rate 
causes a greater rate of heat release, increased peak temperature in the reaction zone which, in turn, increases the heat conduction rate to adjacent fuel, thus accelerating the smolder spread rate. This sequence implies that the smolder reaction zone may well move through a layer of fuel without fully consuming the solid at any point; this unconsumed material acts, in fact, like an insulator for the reaction zone, increasing its stability, as indicated previously

Figure 2 shows measured reverse smolder velocities for several types of fuel as a function of air flow velocity through the fuel bed. The bulk densities of the fuel bed are all low but typical for these types of materials. Note that the air flow velocity range is also quite low but flows much higher than this are sufficient to move the fuel particles in the bed (i.e., an upward flow higher than about $1-2 \mathrm{~cm} / \mathrm{s}$ would fluidize the fuel bed).

Despite the considerable variation in the chemical nature of these fuels, the smolder velocity is always of order $10^{-2} \mathrm{~cm} / \mathrm{s}$. For the same air supply rate, the smolder velocities do not vary much more than a factor of two. This is consistent with the idea that oxygen supply rate dominates the propagation process, not reaction kinetics. The differences that do exist appear to mainly reflect variations in available heat and effective thermal conductivity.

Only limited information is available on toxic gas production from this mode of smoldering. The molar percentage of carbon monoxide in the evolved gases has been examined for two of the fuels in Fig. 2. For the flexible polyurethane foam, the $C O$ is $6-7 \%$ for an air velocity of $0.15 \mathrm{~cm} / \mathrm{s}$; the flow 
rate dependency was not examined [8]. For the cellulosic insulation material [9], the co mole fraction varies from about $10 \%$ to $22 \%$ as one goes from the lowest to the highest air velocity in Fig. 2. The mass flux of Co from such a smoldering process (grams of $\mathrm{CO} / \mathrm{cm}^{2}$ of smolder front/second) then is estimated as follows:

$$
\mathrm{Y}_{\mathrm{CO}}\left(\dot{\mathrm{m}}_{\mathrm{AIR}}+\dot{\mathrm{m}}_{\mathrm{GS}}\right)
$$

or

$$
Y_{\mathrm{CO}}\left[\rho_{\text {AIR }} \mathrm{v}_{\mathrm{AIR}}+(1-\phi) \Delta \rho_{\mathrm{s}} \mathrm{v}_{\mathrm{s}}\right]
$$

Here $\mathrm{Y}_{\mathrm{CO}}$ is the mass fraction of $\mathrm{CO}$ in the evolved product gases (approximately equal to the mole fraction); $\dot{\mathrm{m}}_{\mathrm{AIR}}$ is the mass flux of air entering the smolder zone; $\dot{\mathrm{m}}_{\mathrm{GS}}$ is the mass flux of gaseous material evolved from the solid fuel; $\rho_{A I R}$ is the density of the air at the point where its velocity $\mathrm{v}_{\mathrm{AIR}}$ is measured; $\phi$ is the inftial vold fraction of the fuel bed; $\Delta \rho_{s}$ is the change in density of the fuel bed (for reverse smolder, typically $65-95 \%$ of the original mass is gasified); $v_{s}$ is the smolder front velocity.

Limited information is also available on the aerosol emitted by a reverse smolder source [11]; this is pertinent to detection of a smoldering fire. The source studied was essentially identical to that used to obtain the data for curve B in Fig. 2; the fuel again was an unretarded cellulosic insulation. The mass mean particle size of the aerosol was $2-3 \mu \mathrm{m}$; this is about 5 times larger than cigarette smoke and 50-200 times larger than the sooty particulate produced by flaming combustion. This large size explains the relatively poor 
sensitivity that ionization smoke detectors have for realistic smolder sources. The residual solid left in the smolder wave and the original fuel both were found to be effective filters for this aerosol; this helps explain the observation by Palmer [5] that smoldering in a thick layer of fuel was not detectable until it neared the surface exposed to the ambient atmosphere.

The rate of heat release for this mode of smolder can be estimated from the total mass flux of products and their heat content (gas temperature typically $400-600^{\circ} \mathrm{C}$ ). The result is a few tenths of a watt per square centimeter of smolder front. This translates to a few tens of watts for a reverse smolder source $10-15 \mathrm{~cm}$ in diameter. The strength of the heat source bears on the behavior of the buoyant plume (see section on fire plumes). Sources as weak as those considered here generate plumes that may not reach the ceiling of a room.

Forward Propagation. The second limiting case of one-dimensional smolder propagation is called forward smolder; in this case the oxygen flow is in the same direction as the movement of the smolder front. The most familiar example (though it is not one-dimensional) is a cigarette during a draw. This case is encountered in some industrial combustion processes but is unlikely to be found in its pure, one-dimensional form in a fire context; some elements of this mode are encountered in realistic cases, however. Some of its characteristics are briefly mentioned here to convey a sense of the major effects that reversing the oxygen flow direction can have on smolder propagation characteristics. 
Forward and reverse smolder propagation were compared in references 6 and 9; the fuel was an unretarded cellulosic insulation. Forward smolder through this same fuel at the same air supply rate is about ten times slower than reverse smolder. The Co mole fraction is independent of air supply rate and is about $9 \%$. Forward smolder gives more complete combustion of the fuel. These and other differences between the two smolder modes can be explained in terms of the differing wave structures [6].

\section{II-B) Multi-Dimensiona 1 Smolder Spread}

Factors such as ignition source geometry, fuel geometry and the strong influence of buoyant flow on oxygen supply usually interact to assure that a smolder reaction zone has significant gradients of temperature and species in two or three dimensions. The number of possible configurations is then virtually limitless. The practical configurations that have been studied are few and they are usually two dimensional; they do shed some light on most cases likely to be of interest.

Horizontal Fuel Layer. The configuration that has been studied most extensively is that of two-dimensional smolder propagation in a uniform horizontal layer of particles or fibers. Ohlemiller [12] examined the structure of the smolder zone in a thick $(18 \mathrm{~cm})$ horizontal layer of cellulosic insulation in the absence of any forced air flow over the fuel layer. In these conditions, the flow induced by the buoyant plume rising above the smolder zone assures a constant supply of oxygen to the space above the layer; oxygen penetration of the layer is largely by diffusion. 
If such a layer is ignited uniformly on one end, the smolder reaction zone soon evolves into a new shape dictated by oxygen supply rates [12]. The uppermost elements of the reaction zone, being closest to the free surface and, hence, ambient air, spread away from the ignition source the fastest; successively deeper elements spread in the same direction more slowly. The result is a smolder reaction zone that, viewed in vertical cross-section, slopes upward, from the bottom of the layer to the top, in the direction of movement. The steady-state length of this inclined smolder front is roughly twice the depth of the original fuel layer. This inclined reaction zone is several centimeters thick and across this thickness there is a smooth transition from unburned fuel to ash. On the ash side (the free surface adjacent to air) oxygen diffuses down and inward in the same direction as the smolder front is moving and attacks the charred fuel; this aspect is analogous to forward smolder discussed above. On the unburned fuel side of the inclined smolder front, oxygen diffuses in from the region ahead of the front to react with the fuel as it is thermally degraded by heat conducted from the char oxidation region. Oxygen here is moving opposite to the direction of smolder propagation so this aspect of the overall reaction zone is analogous to reverse smolder. It was pointed out previously that in cellulosic materials, this oxidative/thermal degradation is exothermic. Thus the two dimensional horizontal smolder zone incorporates features of both forward and reverse smolder and is driven forward by the combined heat release from char oxidation and oxidative/thermal degradation.

The participation of oxidative/thermal degradation in driving the smolder process requires that oxygen have free access to the thermal degradation region. For a low permeability fuel such as solid wood this is not the case. 
Even though solid wood has basically the same reaction chemistry as cellulosic insulation (which consists mostly of wood fibers) and smolders with a qualitatively similar inclined reaction zone, it must be driven solely by char oxidation.

The low permeability and corresponding high density of solid wood has another consequence with regard to smolder. The self-insulating quality of the reaction zone is much less than it is with a low density layer of fuel particles or fibers. A single layer of wood will not sustain smolder unless it is subjected to an additional heat input of about $1 \mathrm{~W} / \mathrm{cm}^{2}$ [13]; this could come from some external radiant source or from another piece of smoldering wood which has an adequate radiative view factor with respect to the first:

In view of the previously noted, strong role of oxygen supply rate in shaping the smolder process in a horizontal fuel layer, it is not surprising that it also accelerates in response to an increased oxygen supply rate produced by an air flow over the top of the smoldering layer. As with the one-dimensional propagation situation, one again has two possibilities: the air flow can go in the same direction as the smolder front (again called forward smolder) or the opposite direction (reverse smolder). Note, however, that now the actual fluxes of oxygen within the smoldering fuel bed may go in various directions; they are no longer constrained to be parallel to the smolder wave movement, as in the one-dimensional cases.

Palmer [5] examined both of the flow direction possibilities for. relatively thin horizontal layers $(0.3$ to $5.7 \mathrm{~cm}$ ) of various cellulosic particles (cork, deal, beech, grass); Fig. 3 shows some typical results. Note 
that the smolder velocities are generally much slower than in Fig. 2 despite the much higher air velocities. Much of the difference is probably due to differing rates of actual oxygen delivery to the reaction zone and to the fact that the near-surface region which gets the best oxygen supply is also subjected to the highest heat losses.

The influence of two factors is shown in Fig. 3, fuel particle size and relative direction of air flow and smolder propagation. Particle size has a relatively weak effect on smolder velocity but its effect depends on whether the smolder configuration is forward or reverse. The configuration itself has a much greater effect.

Ohlemiller [14] obtained comparable smolder velocities and dependence on configuration for 10-11 cm thick layers of cellulosic insulation. It was found that the configuration dependence cannot be explained solely on the basis of oxygen supply rates. The mass transfer rate to the surface of the fuel bed was measured for forward and reverse configurations; it differs by only $20-30 \%$ (these differences are caused by changes in the bed shape due to shrinkage during smolder). It was pointed out that the observed dependence on relative direction of the air flow is consistent with there being a prominent role for convective heat transfer along the top surface of the fuel layer. This can only be so if part of the smolder wave, i.e., the region near the leading edge, is kinetically-limited (and therefore highly temperature sensitive) rather than oxygen supply rate-limited. This idea explains the qualitative impact of both relative air flow direction and combustion retardants on smolder velocity; it also explains why forward smolder is faster than reverse smolder in the horizontal layer configuration whereas the 
opposite was seen to be true for one-dimensional propagation. The role played by fuel particle size may be implicit in this view but a quantitative model is not yet available.

There is a minimum thickness below which a horizontal fuel layer will not undergo self-sustained smolder propagation. As the thickness of a fuel layer decreases, its surface to volume ratio increases (inversely with thickness to the first power). The ratio of the rate of heat loss to the rate of heat generation varies in this manner also so that ultimately the losses are overwhelming and extinction occurs. The exact thickness will depend on factors influencing the heat generation per unit volume at a given thickness such as bulk density, fuel type and particle size, rate of oxygen supply, etc. The same considerations apply to other thin layers of fuel such as fabrics on upholstery and sheets of paper, wood or particle board. Palmer [5] found that the minimum depth for sustained smolder in still air increased linearly with particle size for beech, deal and cork; for cork this dependence ceased above $0.2 \mathrm{~cm}$, apparently because more complete oxidation of the char stabilized the process in the layers of larger particles. For very small particles, ( $<100 \mu \mathrm{m}$ ) the minimum depth dropped as low as $1 \mathrm{~mm}$ for cork dust; $1 \mathrm{~cm}$ was typical of small particles of beech or deal sawdust. Ohlemiller and Rogers [15] found the minimum depth in still air for an unretarded cellulosic insulation to be $3-1 / 2 \mathrm{~cm}$; a heavy loading of the smolder retardant boric acid roughly doubled this value. Since the insulation has a very small effective particle size and essentially the same chemistry as Palmer's sawdusts, most of the difference in minimum depth (for the unretarded material) probably lies in the bulk density which is about four to five times less for the insulation compared to the sawdusts $(0.04 \mathrm{~g} / \mathrm{cc}$ vs. $0.18 \mathrm{~g} / \mathrm{cc})$. Palmer found that the 
minimum depth dropped rapidly with increased air flow over the sawdust layers, in keeping with the idea that a greater rate of heat release per unit volume stabilizes the smolder process.

Smolder propagation data on a few other fuels (including some that are inorganic) in horizontal layers can be found in reference 15. Unfortunately neither here nor in the previous references on horizontal layer smolder is there any data on the evolved products. For crude estimates on cellulosic materials the previous results for reverse smolder are adequate but they should be applied here with caution.

Other Fuel Configurations. Data on a few other multi-dimensional smolder configurations are summarized in Table 1 . Again there is little more available than the rate of smolder propagation. All the materials in Table I are fairly porous. As noted previously, solid wood also smolders given a configuration that limits heat losses; available data on rates are extremely limited, however. Reference 32 reports rough measurements for smolder spread on $3.8 \mathrm{~cm}$ thick slabs of white pine. Two vertical slabs formed a gap up which air flowed at $10 \mathrm{~cm} / \mathrm{s}$. Upward (forward) spread was at about $10^{-2} \mathrm{~cm} / \mathrm{s}$; downward (reverse) spread was at $2 \cdot 10^{-3} \mathrm{~cm} / \mathrm{s}$.

The last type of smolder configuration mentioned in Table 1 is quite pertinent to the scenario which makes smoldering a major contributor to residential fire deaths, i.e., upholstery and bedding fires initiated by cigarettes. This is frequently a composite problem with the smoldering tendency of both the fabric and the substrate (polyurethane foam, cotton batting) pertinent to the overall smolder behavior of the combined assembly 
[23]. Ortiz-Molina, et al. have shown that the combination of a cellulosic fabric plus a polyurethane foam can smolder over a substantially wider range of conditions than can the foam alone [24]. The fabric smolder process supplies added heat to the foam smolder zone while competing for oxygen at the same time. The full complexity of this interaction is yet to be explored. A considerable amount of empirical data on the tendency of cigarettes to initiate this type of smolder is available [25-28,40].

The life hazard posed by smoldering bedding or upholstery within a closed room has been studied to some extent [29-31]. In ref. 30 data are presented on the build-up of co (near the ceiling) in a room $2.4 \mathrm{~m}$ on a side due to cigarette-initiated smolder in a cotton mattress. The smolder front was reported to spread radially at a rate of $6.310^{-3} \mathrm{~cm} / \mathrm{s}$ independently of the size of the smoldering area. In two out of five tests the smolder process underwent a transition to flaming combustion after 65-80 minutes. This is close to the time at which the authors estimated that the total carbon monoxide exposure was lethal. In ref. 30 similar data are reported for a greater variety of bedding and upholstery materials; these were ignited by cigarettes (and by flaming sources) in a room $4.3 \times 3.6 \times 2.4 \mathrm{~m}$. Carbon monoxide and several other gases were sampled at three locations. Flaming developed from smoldering in several of the tests usually requiring $2-3$ hours of smoldering first; again the total exposure to carbon monoxide from the smolder smoke was near or exceeded lethality. Lethal conditions due to carbon monoxide were reached in much shorter times in some cases.

In ref. 31, all available data on the hazards of smoldering in a closed room were evaluated; it was concluded that the probability of a lethal co dose 
and of transition to flaming are comparable for a period from 1 to $21 / 2$ hours

after cigarette initiation of smoldering. A model is presented for build-up of co due to a smoldering fire; the results generally show reasonable agreement with experiment though some of the input parameters must be forced a bit.

\section{II ) Transition to Flaming}

The transition process from smolder to flaming in the above bedding and upholstery fires is essentially spontaneous. At room conditions both smoldering and flaming are possible in many such systems; Sato and Sega [36] explored the domain of overlapping smolder and flaming potential for cellulosic materials and noted a hysteresis in the spontaneous transition between these two combustion modes. The mechanism of such a spontaneous transition has not been investigated in detail. It has been suggested, on the basis of small mock-up studies, that a chimney-like effect develops in the crevice between the horizontal and vertical cushions of a smoldering chair [33]; the enhanced air supply presumably accelerates local char oxidation, heating the char to the point where it can ignite pyrolysis gases. Such a mechanism is plausible but it has not been demonstrated to be operable in real upholstery or bedding where the chimney effect may not develop so readily.

Transition to flaming (fast exothermic gas phase reactions) requires both a mixture of gases and air that are within their flammability limits and a sufficient heat source to ignite this mixture. Furthermore these two requirements must be realized at the same locus in space and at the same time. Anything which either enhances the net rate of heat generation or decreases the net rate of heat loss will move the smoldering material toward flaming 
ignition both by increasing local temperature and rate of pyrolysis gas generation. Such factors include an enhanced oxygen supply, an increase in scale (which usually implies lesser surface heat losses per unit volume of smoldering material) or an increasingly "concave" smolder front geometry, which reduces radiative losses to the surroundings and enhances gaseous fuel concentration build-up. All of these factors may be operating simultaneously in the case of upholstery and bedding smolder; sequential photos in ref. 33 of smolder initiation, growth and transition to flaming in an upholstered chair appear consistent with this idea.

A further factor, in the above case and in other systems involving cellulosic materials is secondary char oxidation. This process is quite similar to after-glow seen in cellulosic chars left by flaming combustion. Intense, high temperature (probably $>800^{\circ} \mathrm{C}$ ) reaction fronts propagate intermittently in seemingly random directions through the fibrous low density char left by the main lower temperature smolder front. In charred fabrics these glowing fronts can sometimes progress stably along the charred residue of a single fiber, in spite of very high heat losses per unit volume of fuel. Such a process requires the catalytic action of alkali metals frequently found naturally in cellulosics or left there during manufacture [35]. While a very hot smolder front the size of a single fiber is unlikely to be sufficiently energetic to ignite flammable gases, the larger fronts (few $\mathrm{mm}$. to $\mathrm{cm}$. in scale) may well be. A process analogous to this has been found to cause occasional flaming ignition of smoldering, unretarded cellulosic insulation [12]. 
The transition from smolder to flaming can also be induced by, for example, a forced increase in oxygen supply rate to the smolder reaction zone $[5,8,36,37,38]$. This was first studied quantitatively by Palmer [5] for air flow over horizontal layers of wood sawdust; it is, of course, a process that is familiar to anyone who has started a camp fire from tinder and sparks. Transition to flaming was noted by Palmer only for air flow in the same direction as smolder propagation (forward smolder); depending on the material, the transition occurred at air flow velocities from about 90 to $170 \mathrm{~cm} / \mathrm{s}$. For these materials flaming did not develop when the mean particle size was less than $1 \mathrm{~mm}$. Ohlemiller [37] did obtain transition to flaming in fibrous insulation material of very small diameter $(\sim 25 \mu \mathrm{m})$ but again only with forward smolder; this occurred at air velocities of about $200 \mathrm{~cm} / \mathrm{s}$ for unretarded insulation. Leisch [38] utilized ignition sources placed midway along the length of his grain and wood particle fuel layers so that he simultaneously obtained forward and reverse smolder zones; flaming was noted at 4 $\mathrm{m} / \mathrm{s}$ air velocity only after the smoldering process produced a substantial depression or cavity in the surface of the fuel layer.

Ohlemiller [37] explained the weak response and lack of flaming transition in reverse smolder on the basis of heat transfer effects influencing the leading edge of the smolder reaction zone. These heat transfer effects intensify the smolder in the leading edge region for forward smolder. In the case of cellulosic insulation the intensification leads to random development of small ( $\mathrm{few} \mathrm{cm}$ ) cavities near the leading edge which act as flame initiation regions and flame holders. 
Ohlemiller also found that both boric acid (a smolder retardant) and borax (a flame retardant) could each eliminate the transition to flaming when the retarded cellulosic insulation was the only fuel. However, their effectiveness was substantially reduced if the smoldering fuel abutted unretarded wood; heat transferred from the smolder zone readily ignited the wood. Palmer [39] noted similarly that layers of fine dust that would not themselves undergo transition to flaming readily ignited adjacent flammable materials.

\section{IV) Concluding Remarks}

Smoldering is a branch of solid fuel combustion quite distinct from flaming in many aspects but equally diverse and complex. Unfortunately it has not been studied nearly to the same extent. This is quite apparent in the lack of quantitative guidelines provided here for estimating the behavior of realistic smolder propagation processes, smolder detection, toxic gas production and the transition to flaming. The experimental data provided can be readily used for closely analogous situations; they must be used cautiously for dissimilar conditions. The reader should always bear in mind the strong role that oxygen supply rate plays with smolder processes. The other most important factor is the relative direction of movement of oxygen supply and smolder propagation; this can be somewhat obscure in many realistic configurations. The actual chemical nature of the fuel is relatively secondary at least with regard to smolder rate; it may be important for toxic gas production rates, but the data here are quite limited. 


\section{References}

1. Clarke, F. and Ottoson, J., Fire J., May 1976, p. 20.

2. McCarter, R., "Smoldering Combustion of Cotton and Rayon", J. Cons. Prod. Flamm. 4 (1977) 346.

3. Bowes, P., Self Heating: Evaluating and Controlling the Hazards, Elsevier, New York, 1984, chap. 7.

4. Ohlemiller, T., Modeling of Smoldering Combustion Propagation, to appear in Progress in Energy and Combustion Science.

5. Palmer, K., Smoldering Combustion in Dusts and Fibrous Materials, Combustion and Flame 1, (1957) 129-154.

6. Ohlemiller, T. and Lucca, D., An Experimental Comparison of Forward and Reverse Smolder Propagation in Permeable Fuel Beds, Combustion and Flame 54, (1983) 131-147.

7. Ohlemiller, T., Bellan, J., and Roger, F., A Model of Smoldering Combustion Applied to Flexible Polyurethanes, Combustion and Flame 36, (1979) 197-215.

8. Rogers, F., and Ohlemiller, T., Smolder Characteristics of Polyurethane Foams, J. Fire Flamm. 11, (1980) 32-44.

9. Lucca, D., An Investigation of Co-Current and Counter-Current Smoldering Combustion in Particulated Fuel Beds, MSE Thesis, Dept. of Mech. and Aero. Eng., Princeton Univ., Oct. 1979.

10. Davidson, B., Keitelman, E., O'Such, W., Smoldering Aspects of Rigid Polymeric Insulation Foams, Rutgers Univ., Dept. of Chem. and Biochem. Eng., Final Report to the Products Research Committee, June 1979.

11. Mulholland, G., and Ohlemiller, T., Aerosol Characterization of a Smoldering Source, Aerosol Sci. and Tech., 1, (1982) 59-71.

12. Ohlemiller, T., Smoldering Combustion Hazards of Thermal Insulation Materials, National Bureau of Standards, NBSIR 81-2350 (1981).

13. Ohlemiller, T., Unpublished results on yellow pine.

14. Ohlemiller, T., Forced Smolder Propagation and the Transition to Flaming in Cellulosic Insulation, National Bureau of Standards, NBSIR 85-3212, August 1985.

15. Ohlemiller, T. and Rogers, F., Cellulosic Insulation Material II. Effect of Additives on Some Smolder Characteristics, Combust. Sci. Technol. 24 (1980) 139-152. 
16. Cohen, L. and Luft, N., Combustion of Dust Layers in Still Air, Fuel 34 (1955) 154-163.

17. Brenden, J. and Schaffer, E., Smoldering Wave-Front Velocity in Fiberboard, USDA Forest Products Laboratory Research Paper, FPL-367, Sept. 1980 .

18. Kinbara, T., Endo, H., and Sega, S., Downward Propagation of Smoldering Combustion through Solid Materials, Proceedings of the Eleventh Symposium (International) on Combustion, The Combustion Institute, Pittsburgh, (1967) 525-531.

19. Egerton, A., Gugan, K., and Weinberg, F., The Mechanism of Smoldering in Cigarettes, Combust. Flame 7 (1963) 63-78.

20. Gann, R., Earl, W., Manka, M•, and Miles L., Mechanism of Cellulosic Smoldering Retardance by Sulfur, Proceedings of the Eighteenth Symposium (International) on Combustion, The Combustion Institute, Pittsburgh (1980) 571-577.

21. Donaldson, D., Yeadon, D., and Harper, K., Smoldering Characteristics of Cotton Upholstery Fabrics, Text. Res. J., March (1983) 160-164.

22. Donaldson, D., Yeadon, D., and Harper, R., Smoldering Phenomenon Associated with Cotton, Text. Res. J., March (1983) 160-164.

23. Tesoro, G. and Toong, T.-Y., Smoldering in Cotton Upholstery Fabrics and Fabric/Cushioning Assemblies, Final Report to Cotton Inc. from MIT Dept. of Mechanical Engineering, Cambridge, Mass. (Feb. 1981).

24. Ortiz-Molina, M., Toong, T-Y., Moussa, N., and Tesoro, G., Smoldering Combustion of Flexible Polyurethane Foams and Its Transition to Flaming or Extinguishment, Proceedings of the Seventeenth Symposium (International) on Combustion, The Combustion Institute, Pittsburgh (1979) 1191-1200.

25. Damant, G., A Survey of Upholstery Fabrics and Their Flammability Characteristics, J.F. F. Consumer Prod. Flamm. 2, (March 1975).

26. Damant, G., Cigarette Induced Smoldering of Uncovered Flexible Polyurethane Foams, J.F. F. Consumer Prod. Flamm. 2 (June 1975) 140.

27. Damant, G., Home Furnishings Fire Retardant Requirements: The California Experience, J. Consumer Prod. Flamm. 6, (June 1979) 95.

28. Palmer, K. and Taylor, W., Fire Hazards of Plastics in Furniture and Furnishings: Ignition Studies, J. F. F. Consumer Prod. Flamm. 1 (June 1974) 186.

29. Sumi, K. and Williams-Leir, G., Lethal Effects of Mattress Fires, National Research Council of Canada, Division of Building Research, Research Paper No. 402, Ottawa, Canada (May 1969). 
30. Hafer, C. and Yuill, C., Characterization of Bedding and Upholstery Fires, Southwest Research Institute Final Report on National Bureau of Standards Contract No. CST-792-5-69, San Antonio, Texas (March 1970).

31. Quintiere, J., Birky, M., McDonald, F., and Smith, G., An Analysis of Smoldering Fires in Closed Compartments and Their Hazard Due to Carbon Monoxide, National Bureau of Standards, NBSIR 82-2556 (July 1982).

32. Ohlemiller, T. and Rogers, F., Smoldering Combustion Studies of Rigid Cellular Plastics, Princeton University, Dept. of Mechanical and Aerospace Engineering Report No. 1432 (May 1979).

33. Salig, R., Smoldering Behavior of Upholstered Polyurethane Cushioning and Its Relevance to Home Furnishings Fires, Masters Thesis, Massachusetts Institute of Technology, Dept. of Mechanical Eng. (1981).

34. Palmer, K. and Taylor, W., Fire Hazards of Plastics in Furniture and Furnishings; Ignition Studies, Great Britain Building Research Establishment Current Paper CP 18/74, (Feb. 1974).

35. McCarter, R., Smoldering Combustion of Cotton and Rayon, J. Consumer Prod. Flamm. 4 (1977) 346-358.

36. Sato, K. and Sega, S., The Mode of Burning Zone Spread Along Cylindrical Cellulosic Material, J. Fire Sci. 3 , (Jan/Feb. 1985) 26-34.

37. Ohlemiller, T., Forced Smolder Propagation and the Transition to Flaming in Cellulosic Insulation, National Bureau of Standards, NBSIR 85-3212 (August 1985).

38. Leisch, S., Smoldering Combustion in Horizontal Dust Layers, Ph.D. Thesis, University of Michigan, Dept. of Aerospace Engineering (1983).

39. Palmer, K., Dust Explosions and Fires, Chapman and Hal1, London (1973), 287.

40. Loftus, J., "Back-up Report for the Proposed Standard for the Flammability (Cigarette Ignition Resistance) of Upholstered Furniture", PFF-6-76, National Bureau of Standards, NBSIR 78-1438, June 1978. 


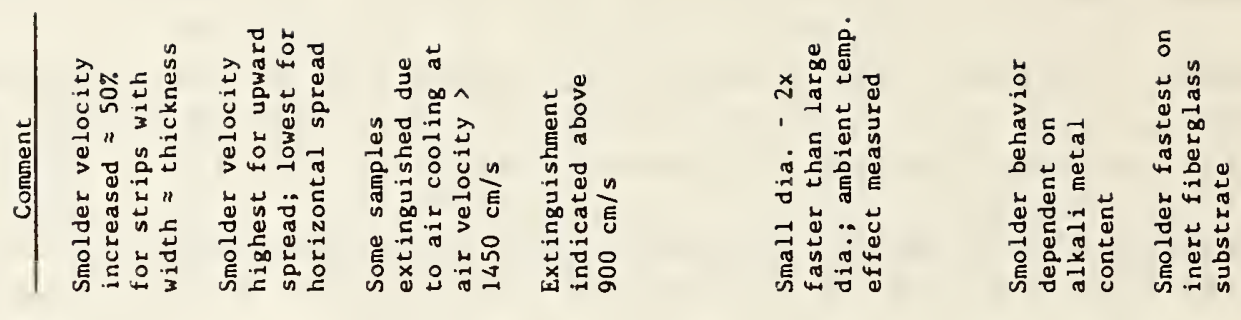

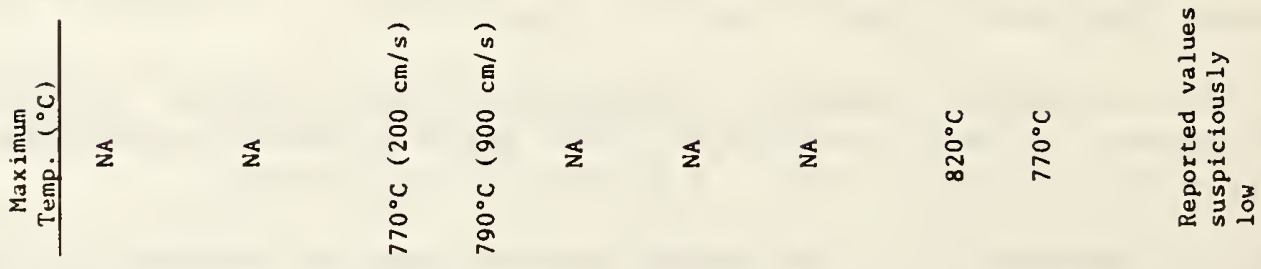

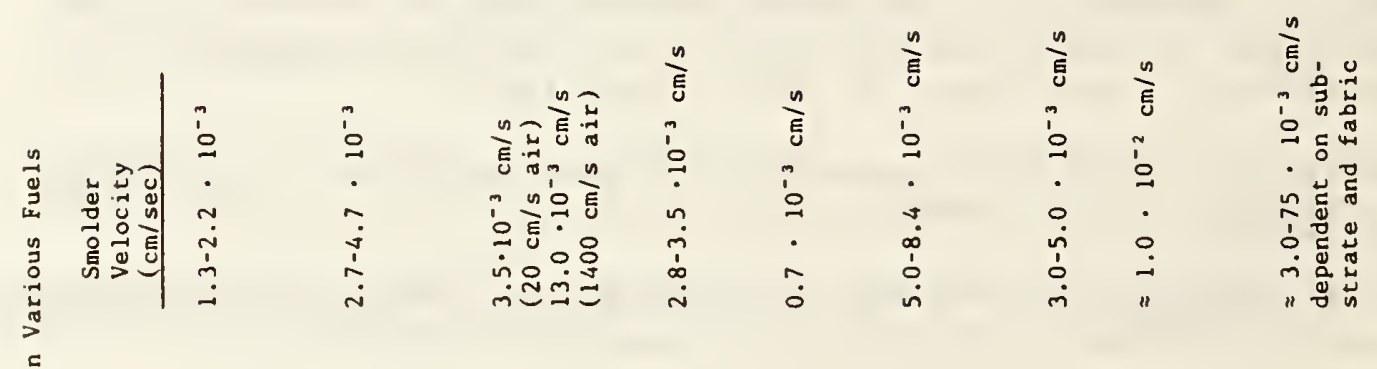

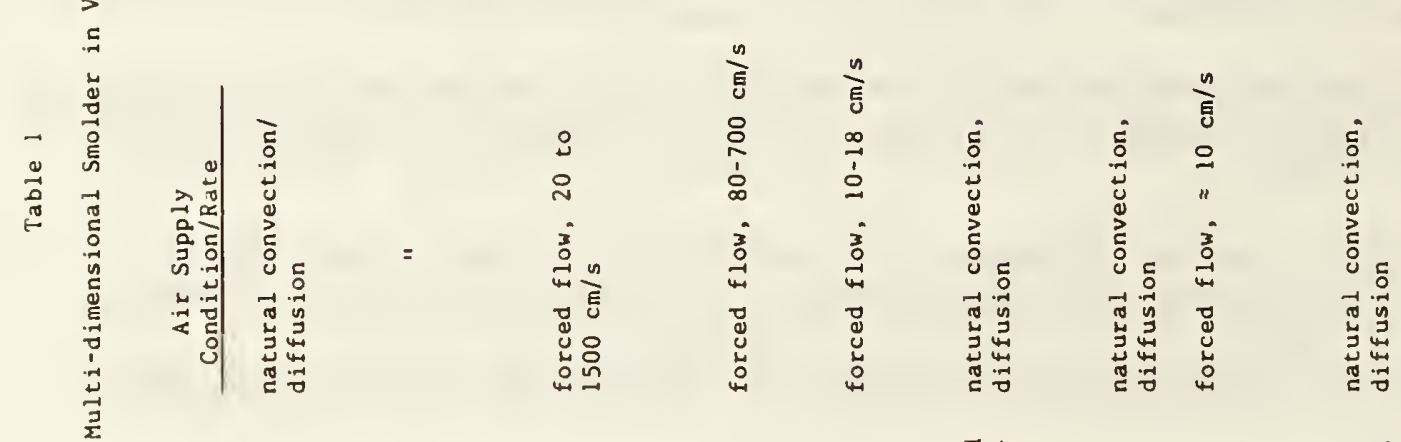

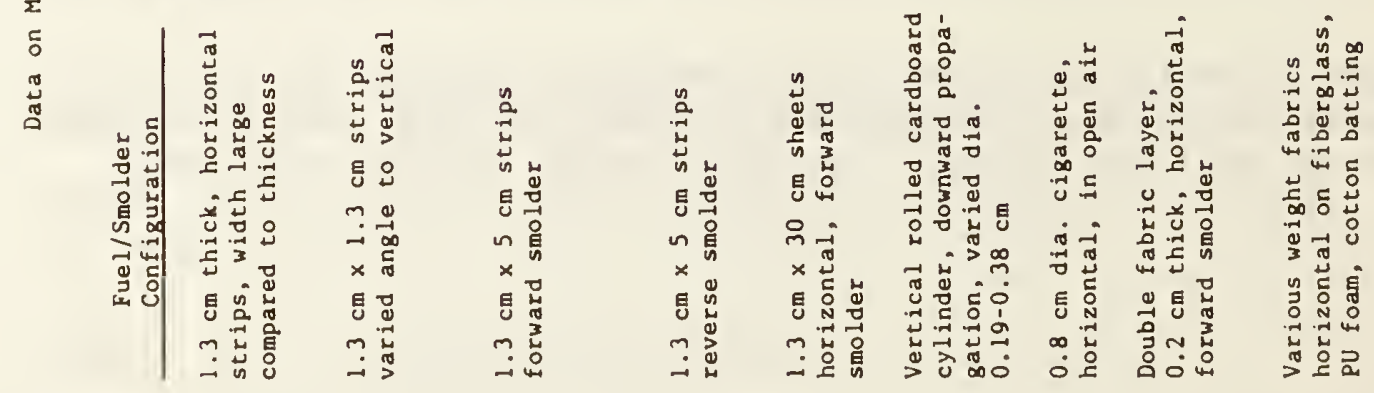

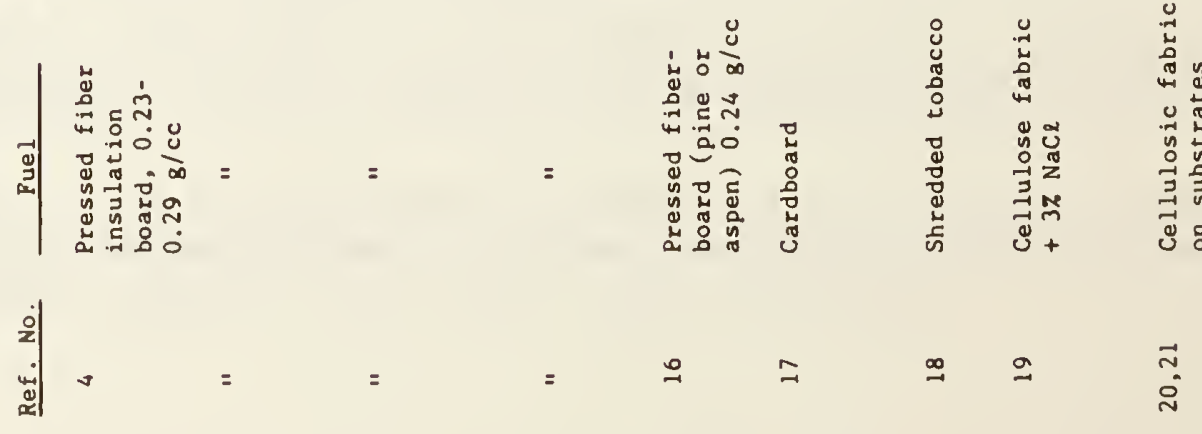




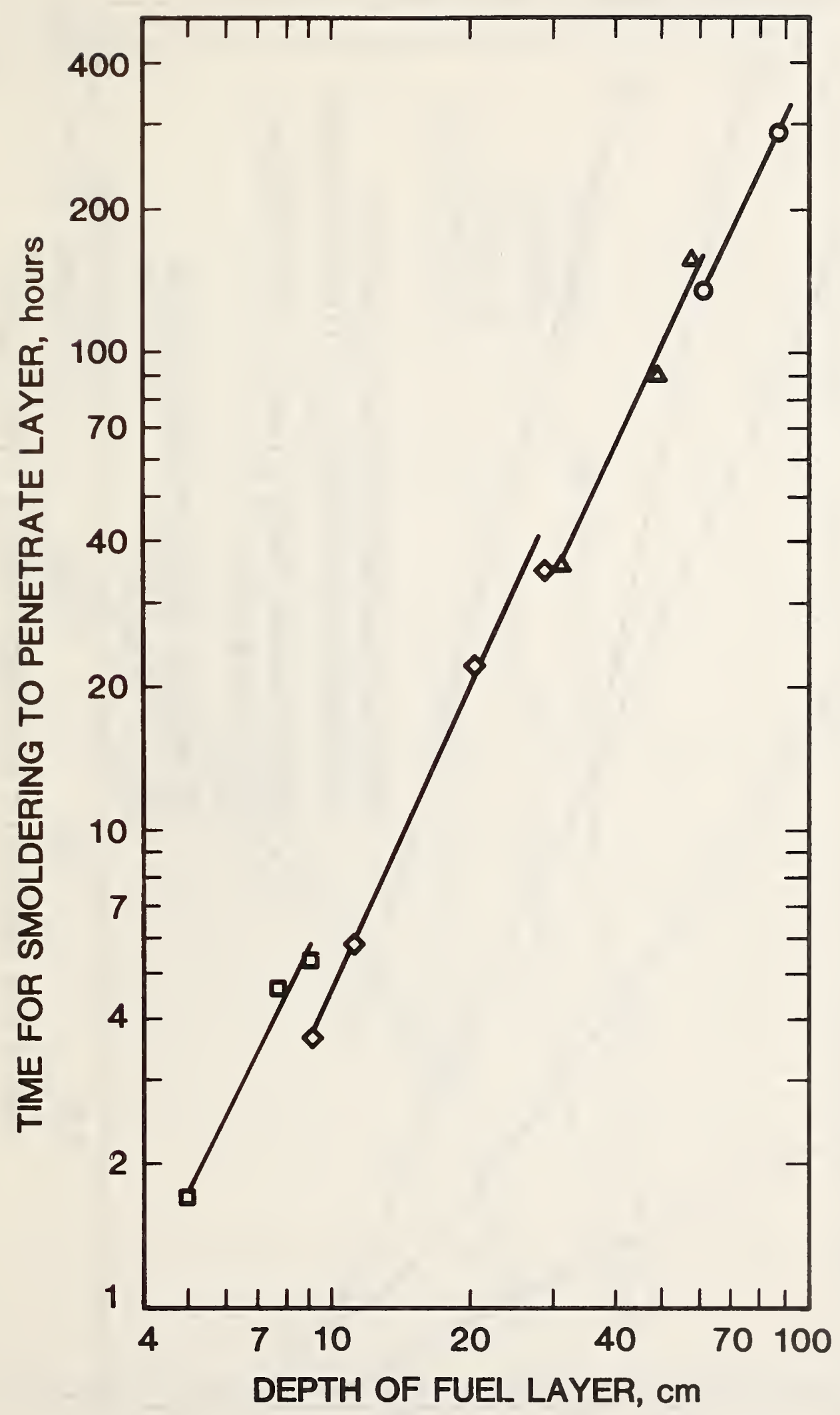

Figure 1. Smoldering upward from bottom within thick layers of mixed wood sawdust (from ref. 4); 口 initiating layer $2.5 \mathrm{~cm}$ deep, $30 \mathrm{~cm}$ square box; $\diamond$ initiating layer $5.2 \mathrm{~cm}$ deep, $30 \mathrm{~cm}$ square box; $\Delta$ initiating layer $5.2 \mathrm{~cm}$ deep, $60 \mathrm{~cm}$ square box; 0 initiating layer $5.2 \mathrm{~cm}$ deep, $90 \mathrm{~cm}$ square box. 


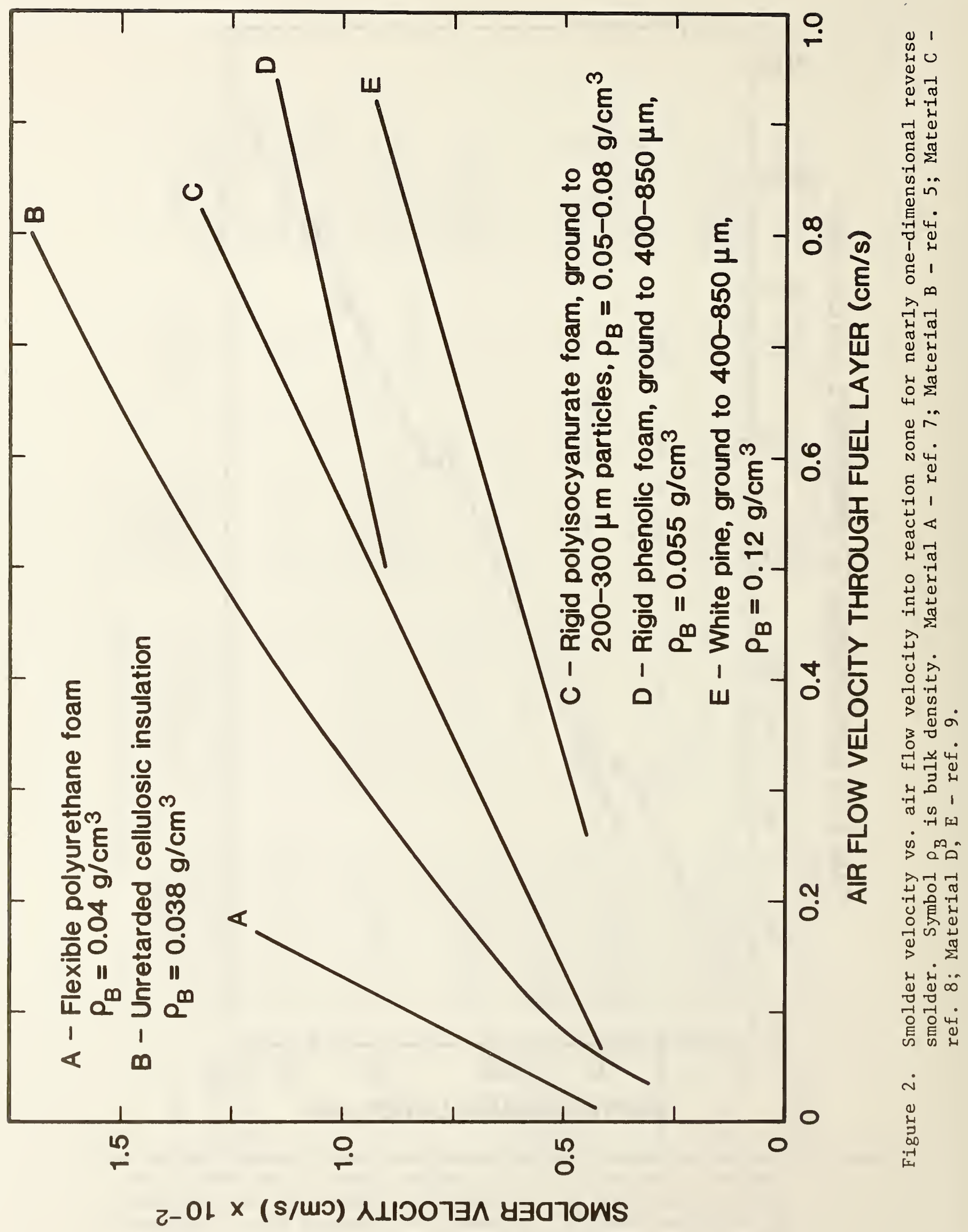




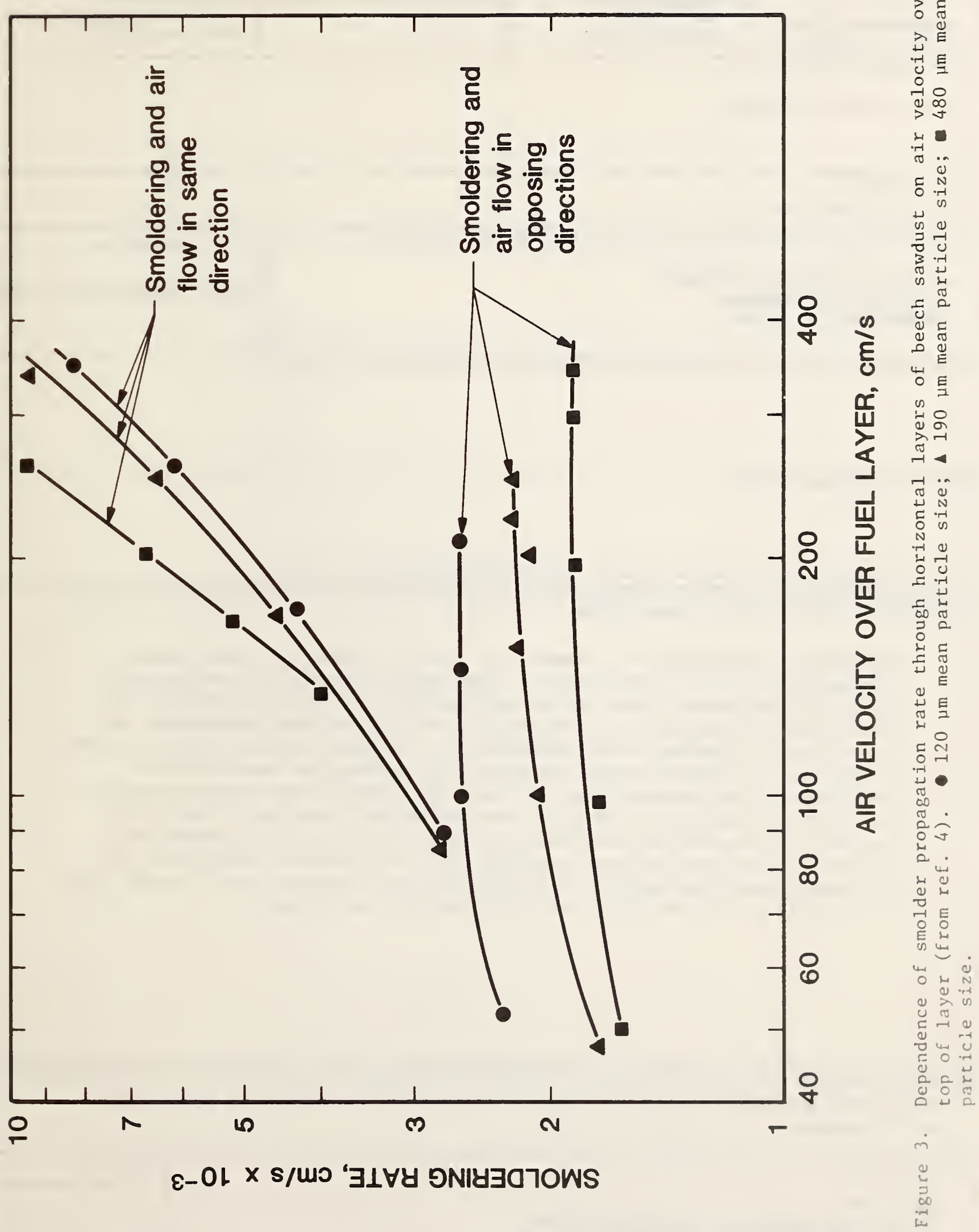


NBS-114A (REV. 2-8C)

U.S. DEPT. OF COMM.

BIBLIOGRAPHIC DATA

SHEET (See instruction s)

1. PUBLICATION OR REPORT NO.

NBSIR 85-3294
2. Performing Organ. Report Nof 3. Publication Date

February 1986

4. TITLE AND SUBTITLE

Smoldering Combustion

5. AUTHOR(S)

T. J. Ohlemiller

6. PERFORMING ORGANIZATION (If joint or other thon NBS, see instructions)

7. Contracd/Grant No.

NATIONAL BUREAU OF STANDARDS

DEPARTMENT OF COMMERCE

WASHINGTON, D.C. 20234

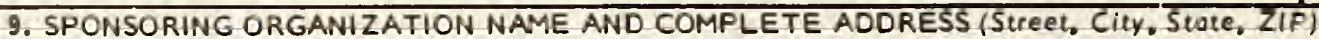

8. Type of Report \& Period Covered

10. SUPPLEMENTARY NOTES

[] Document describes a computer program; SF-185, FIPS Software Summary, is attached.

11. ABSTRACT (A 200-word or less factual summary of most significant information. If document includes a slgnificant bibliogrophy or literoture survey. mention it here)

Smoldering combustion is a common fire safety hazard that contributes substantially to the fire losses in the United States; fire protection engineers thus have a need to be familiar with its characteristics. The post-initiation behavior of smoldering (self-sustaining propagation and transition to flaming) is described here. The most studied cases of propagation are one-dimensional; the underlying mechanisms are described qualitatively and spread rates for several materials are presented along with limited information on toxic gas evolution. Similar, though more limited, information is presented for more realistic multi-dimensional smolder spread, particularly in horizontal fuel layers. Mechanisms for the transition from smolder to flaming are briefly described; limited data on requisite air flows to force the transition are given.

12. KEY WORDS (Six to twelve entries: alphabetical order: capitalize only proper nomes: and separote key words by semicolons) cellulosic materials; flaming combustion; smoldering combustion; propagation; toxic hazards.

13. AVAILABILITY

[X Unimited

For Official Distribution. Do Not Release to NTIS

Order From Superintendent of Documents, U.S. Government Printing Office, Washington, D.C. 20402.
14. NO, OF PRINTED PAGES

15. Price

[ Order From National Technical Information Service (NTIS), Springfield, VA, 2216I 

